\title{
Hexacoordinated Gallium(III) Triazenide Precursor for Epitaxial Gallium Nitride by Atomic Layer Deposition
}

\author{
Polla Rouf," Rouzbeh Samii, "Karl Rönnby, Babak Bakhit, Sydney C. Buttera, Ivan Martinovic, \\ Lars Ojamäe, Chih-Wei Hsu, Justinas Palisaitis, Vadim Kessler, Henrik Pedersen, and Nathan J. O’Brien*
}

Cite This: Chem. Mater. 2021, 33, 3266-3275

Read Online

ACCESS

山ll Metrics \& More

Article Recommendations

Supporting Information

ABSTRACT: Gallium nitride $(\mathrm{GaN})$ is the main component of modern-day high electron mobility transistors due to its favorable electronic properties. As electronic devices become smaller with more complex surface architecture, the ability to deposit high-quality GaN films at low temperatures is required. Herein, we report a new highly volatile $\mathrm{Ga}(\mathrm{III})$ triazenide precursor and demonstrate its ability to deposit high-quality epitaxial GaN by atomic layer deposition (ALD). This new $\mathrm{Ga}$ (III) triazenide, the first hexacoordinated $\mathrm{Ga}-\mathrm{N}$ bonded precursor used in a vapor deposition process, was easily synthesized and purified by either sublimation or recrystallisation. Thermogravimetric analysis showed single-step volatilization with an onset temperature of $155{ }^{\circ} \mathrm{C}$ and negligible residual mass. Three temperature intervals with self-limiting growth were observed when depositing GaN films. The GaN films grown in the second growth interval at 350 ${ }^{\circ} \mathrm{C}$ were epitaxial on $4 \mathrm{H}-\mathrm{SiC}$ without an $\mathrm{AlN}$ seed layer and found to have a near

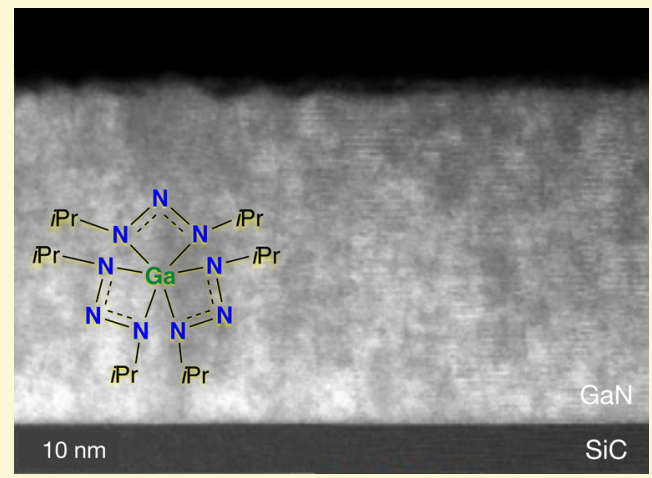
stoichiometric $\mathrm{Ga} / \mathrm{N}$ ratio with very low levels of impurities. In addition, electron microstructure analysis showed a smooth film surface and a sharp interface between the substrate and film. The band gap of these films was $3.41 \mathrm{eV}$ with the Fermi level at $1.90 \mathrm{eV}$, showing that the GaN films were unintentionally n-type-doped. This new triazenide precursor enables ALD of GaN for semiconductor applications and provides a new $\mathrm{Ga}$ (III) precursor for future deposition processes.

\section{INTRODUCTION}

Gallium nitride $(\mathrm{GaN})$ is the key material in state-of-the-art $\mathrm{AlGaN} / \mathrm{GaN}$ high electron mobility transistors used in highfrequency electronics. This is due to its wide and direct band gap, thermal stability, high breakdown field, and electron mobility. ${ }^{1-4}$ High-frequency electronics require electronic grade $\mathrm{GaN}$, preferably deposited on $\mathrm{SiC}$ due to its high thermal conductivity. ${ }^{5}$ However, it is challenging to deposit $\mathrm{GaN}$ directly onto $\mathrm{SiC}$ by chemical vapor deposition (CVD) due to poor wetting of the film onto the substrate. ${ }^{6}$ Therefore, a buffer layer of AlN is required to initiate GaN film growth. ${ }^{7-9}$ CVD is currently used to deposit thin films of GaN at high temperatures between 800 and $1000{ }^{\circ} \mathrm{C} .{ }^{10}$ The high temperatures used are a result of the poor gas-phase chemistry between the routinely used trimethylgallium $\left(\mathrm{GaMe}_{3}\right)$ and ammonia $\left(\mathrm{NH}_{3}\right)$ precursors at low temperatures, which forces $\mathrm{N} / \mathrm{Ga}$ precursor ratios in the order of $10^{3}$. $^{11}$ These hightemperature CVD processes also hinder the deposition of highly conformal thin films of $\mathrm{GaN}$ on complex architecture and temperature-sensitive materials, such as $\mathrm{InN}{ }^{12}$ Atomic layer deposition (ALD) is a low-temperature time-resolved form of CVD, in which the metal and nonmetal precursors are pulsed into the reaction chamber sequentially. This process allows for the deposition of the resulting film to be governed solely by surface chemical reactions. The ALD cycle can be repeated hundreds of times to deposit films with controlled thickness, excellent large-area uniformity, and conformity. Although ALD is routinely used in the production of modern electronic devices, its potential for $\mathrm{GaN}$ is yet to be fully unlocked. This is mostly due to the poor deposition chemistry afforded at low temperatures by the commonly used trialkylgallium(III) precursors. ALD of GaN has been undertaken using $\mathrm{GaMe}_{3}$ and triethylgallium $\left(\mathrm{GaEt}_{3}\right)$ with $\mathrm{N}_{2} / \mathrm{H}_{2}$ plasma, ${ }^{13-15} \mathrm{NH}_{3}$ plasma, ${ }^{13,16,17}$ or thermally with $\mathrm{NH}_{3},{ }^{18}$ but all render polycrystalline films with high $\mathrm{C}$ and $\mathrm{O}$ impurities and nonstoichiometric $\mathrm{Ga} / \mathrm{N}$ ratios.

To date, limited efforts have been made to develop new $\mathrm{Ga}$ (III) precursors for ALD of GaN. Replacing the Ga-C bonds of $\mathrm{GaMe}_{3}$ and $\mathrm{GaEt}_{3}$ with $\mathrm{Ga}-\mathrm{N}$ bonds has led to the formation of tris(dimethylamido)gallium(III) ${ }^{19}\left(\mathrm{Ga}\left(\mathrm{NMe}_{2}\right)_{3}\right)$. We recently used $\mathrm{Ga}\left(\mathrm{NMe}_{2}\right)_{3}$ for the ALD of $\mathrm{GaN}$, which gave crystalline GaN films in a temperature range between 130 and $250{ }^{\circ} \mathrm{C}$. ${ }^{20}$ The films grown were epitaxial on $4 \mathrm{H}-\mathrm{SiC}$ with a

Received: January 22, 2021

Revised: April 9, 2021

Published: April 22, 2021 
Scheme 1. Synthesis of Tris(1,3-diisopropyltriazenide)gallium(III) 1

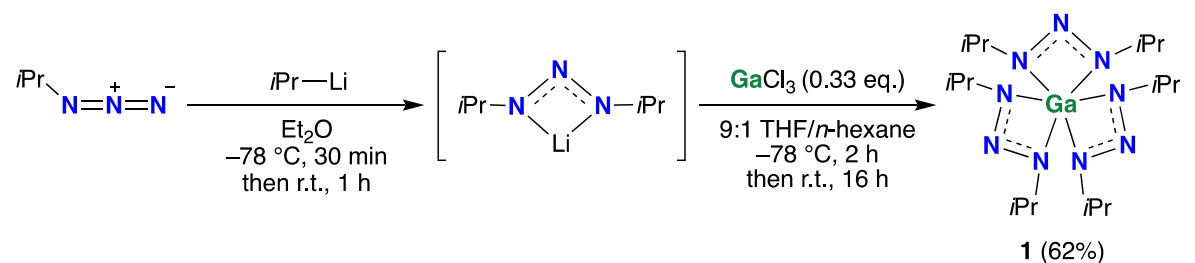

near stoichiometric $\mathrm{Ga} / \mathrm{N}$ composition but contained approximately 2.8 at $\%$ of $\mathrm{C}$ impurities. The $\mathrm{C}$ impurities incorporated in the films were expected, as the deposited surface species from metal amide precursors are known to suffer from low thermal stability. ${ }^{21}$ Alternatively, bidentate ligands have been used in ALD precursor development to improve the thermal stability of a precursor as they provide two stronger chelating bonds to the metal center. This has led to the formation of the homoleptic hexacoordinated $\mathrm{Ga}-\mathrm{N}$ bonded $\mathrm{Ga}(\mathrm{III})$ amidinate $\left(\mathrm{Ga}(\mathrm{amd})_{3}\right)^{22}$ and guanidinate $\left(\mathrm{Ga}(\text { guan })_{3}\right)^{23}$ compounds. Although these compounds showed increased thermal stability in comparison to Ga$\left(\mathrm{NMe}_{2}\right)_{3}$, they lack sufficient volatility to be used in an ALD process. Triazenides are an alternative bidentate ligand that differs from amidinates only by a nitrogen atom in the endocyclic position of the ligand backbone. Although a homoleptic hexacoordinated $\mathrm{Ga}$ (III) triazenide has been reported, ${ }^{24}$ its structure was not revealed, and it is undesirable for vapor deposition due to the 1,3-diphenyltriazenide ligand. We recently reported the first example of homoleptic 1,3dialkyltriazenide, tris(1,3-diisopropyltriazenide)indium(III) $\left(\operatorname{In}(\text { triaz })_{3}\right)$, used in a vapor deposition process. ${ }^{25}$ This new triazenide precursor was highly volatile and used to deposit epitaxial $\mathrm{InN}$ on $4 \mathrm{H}-\mathrm{SiC}$ that was stoichiometric with low levels of impurities. To further explore the 1,3-diisopropyltriazenide ligand, we envisaged its ability to stabilize the $\mathrm{Ga}$ (III) center to give a new precursor for ALD of GaN. Herein, we report the synthesis, structure, and physical properties of tris(1,3-diisopropyltriazenide)gallium(III) 1, and demonstrate it as an excellent ALD precursor for highquality epitaxial GaN thin films on $4 \mathrm{H}-\mathrm{SiC}$. This new $\mathrm{Ga}$ (III) precursor is the first example of a volatile hexacoordinated $\mathrm{Ga}-\mathrm{N}$ bonded precursor used in a vapor deposition process and is shown to possess superior deposition chemistry for GaN over previously used tricoordinated literature precursors.

\section{RESULTS AND DISCUSSION}

2.1. Synthesis and Characterization of the Ga(III) Triazenide Precursor. The synthesis of tris(1,3diisopropyltriazenide)gallium(III) $\mathbf{1}$ is analogous to In(triaz) ${ }_{3}{ }^{25}$ (Scheme 1). Compound $\mathbf{1}$ was isolated in a good yield as a colorless solid after purification by either recrystallization or sublimation at $90{ }^{\circ} \mathrm{C}(0.5 \mathrm{mbar})$. It was stable at room temperature in both solid and solution state under an inert atmosphere. However, 1 decomposes upon air or moisture exposure to give a white insoluble powder thought to be gallium oxide $\left(\mathrm{Ga}_{2} \mathrm{O}_{3}\right)$. Compound $\mathbf{1}$ was fully characterized by nuclear magnetic resonance (NMR) spectroscopy, elemental analysis, and X-ray crystallography.

The crystal structure of $\mathbf{1}$ (Figure 1, Tables S1-S4) showed the $\mathrm{Ga}$ atom in a distorted-octahedral coordination geometry, similar to $\mathrm{In}(\text { triaz })_{3}$ and $\mathrm{Ga}(\text { guan })_{3} \cdot{ }^{23}$ All ligands were distorted over four positions creating a multitude of different

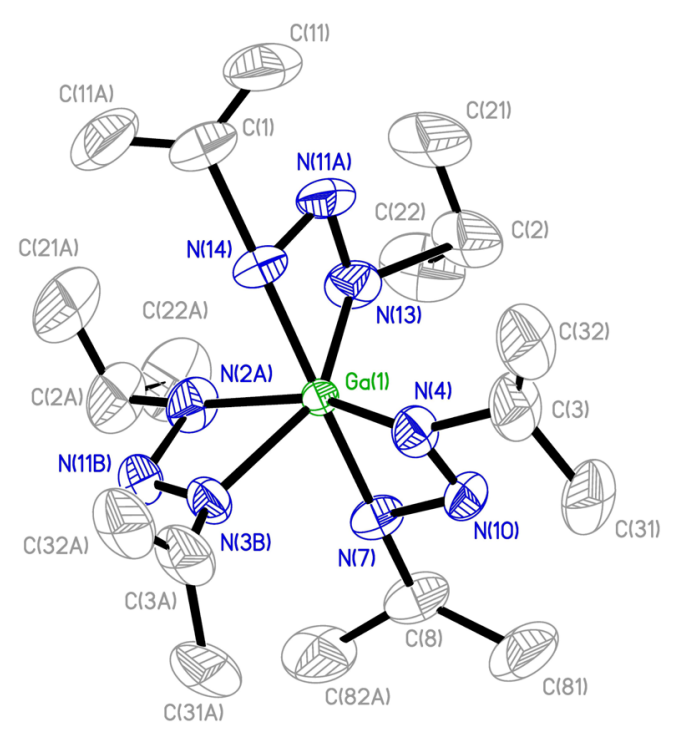

Figure 1. ORTEP drawing of 1 with thermal ellipsoids at the $50 \%$ probability level. All hydrogen atoms were removed for clarity.

orientations. Placement of the molecule was possible by its high symmetry (orthorhombic) and mismatching the inner trigonal symmetry. The Ga-N bond lengths (av 2.09(3) A) were similar to those of $\mathrm{Ga}$ (guan) $)_{3}$ (av 2.09(1) $\AA$ ). ${ }^{23}$ This shows that the electron-withdrawing effect of the triazenide ligand has no effect on the $\mathrm{Ga}-\mathrm{N}$ bond distances.

The ${ }^{1} \mathrm{H}$ NMR spectrum of 1 in $\mathrm{C}_{6} \mathrm{D}_{6}$ showed one septet at $\delta$ $3.96 \mathrm{ppm}$ and one doublet at $\delta 1.26 \mathrm{ppm}$ for the methine proton and methyl groups of the isopropyl moiety, respectively (Figure S1). This result indicates 1 exists as a monomer in the solution state and reflects its crystal structure. Compound 1 was found to be highly volatile and sublimed at $90{ }^{\circ} \mathrm{C}(0.5$ mbar) with no visible solid remaining. Thermogravimetric analysis (TGA) showed the new precursor volatilized completely in a single step between 155 and $225{ }^{\circ} \mathrm{C}$, with $1 \%$ residual mass remaining (Figure 2 ). The derivative TGA showed clean volatilization without any signs of decomposition. A thermal stress test with a higher mass loading of $\mathbf{1}$ displayed a shift to a slightly higher volatilization temperature $\left(160-235{ }^{\circ} \mathrm{C}\right)$ without signs of decomposition (Figure S3a). The 1 Torr vapor pressure of 1 was shown to occur at $136{ }^{\circ} \mathrm{C}$ (Figure S3b), and its $\Delta H$ of vaporization was $73.1 \mathrm{~kJ} \mathrm{~mol}^{-1}$ (Figure S3c). The volatility of $\mathbf{1}$ is strikingly similar to its isostructural analogue $\operatorname{In}(\operatorname{triaz})_{3}$, with slight variation in the sublimation temperature $\left(80{ }^{\circ} \mathrm{C}, 0.5 \mathrm{mbar}\right)$, TGA onset volatilization temperature $\left(145-215{ }^{\circ} \mathrm{C}\right), 1$ Torr vapor pressure $\left(134{ }^{\circ} \mathrm{C}\right)$, and $\Delta H$ of vaporization $(65.8 \mathrm{~kJ}$ $\left.\mathrm{mol}^{-1}\right) .^{25}$ Although it is expected that 1 and $\operatorname{In}(\text { traiz })_{3}$ would have similar chemical properties, their comparable physical properties highlight the significance of the 1,3-diisopropyltriazenide ligand in the group 13 precursor landscape. More 


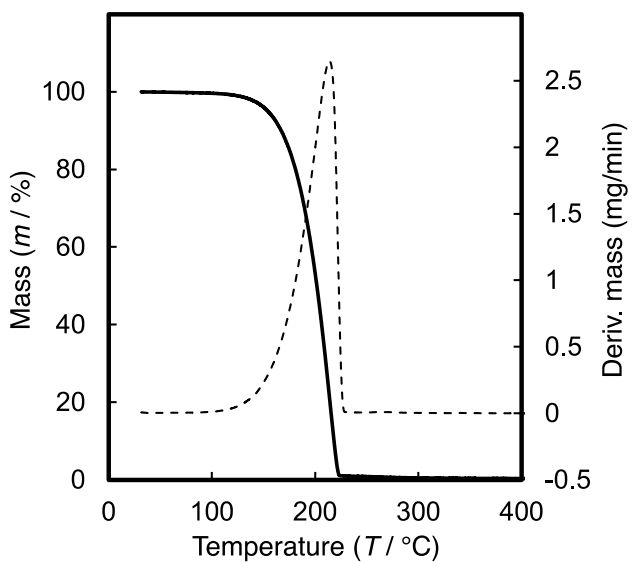

Figure 2. TGA of compound $\mathbf{1}$.

importantly, the volatility of $\mathbf{1}$ is quite remarkable when compared to $\mathrm{Ga}(\mathrm{amd})_{3}$ and $\mathrm{Ga}$ (guan), which are unsuitable for use in an ALD process due to the lack of volatility. ${ }^{22,23}$ This makes compound $\mathbf{1}$ noteworthy, as it is the first example of a highly volatile homoleptic hexacoordinated $\mathrm{Ga}-\mathrm{N}$ bonded $\mathrm{Ga}$ (III) precursor, as far as we know.

The heterolytic bond dissociation energy of the $\mathrm{Ga}-\mathrm{N}$ bonds for 1 was calculated by quantum-chemical density functional theory (DFT) computations to be $341.2 \mathrm{~kJ} \mathrm{~mol}^{-1}$, which is lower than that of $\mathrm{Ga}$ (guan) $)_{3}\left(349.5 \mathrm{~kJ} \mathrm{~mol}^{-1}\right)$ and $\mathrm{Ga}(\mathrm{amd})_{3}\left(373 \mathrm{~kJ} \mathrm{~mol}^{-1}\right)$, indicating a weaker $\mathrm{Ga}-\mathrm{N}$ bond (Table S5). The natural charges of the $\mathrm{Ga}(+1.47)$ and $\mathrm{N}$ $(-0.44)$ atoms of 1 show highly polarized bond character (Table S6). Both the HOMO $\pi$ and LUMO $\pi^{*}$ frontier orbitals of 1 are localized on the $\mathrm{N}_{3}$ moiety of the triazenide ligand (Figure 3a,b) similar to $\operatorname{In}(\text { triaz })_{3}{ }^{25}$ This provides a)

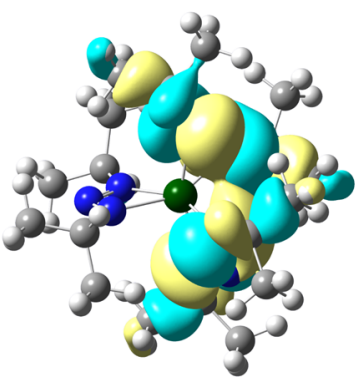

b)

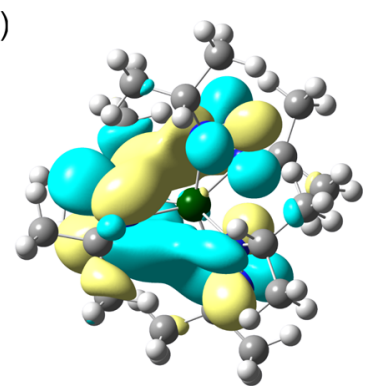

Figure 3. (a) HOMO $(-5.87 \mathrm{eV})$ and (b) LUMO $(-0.72 \mathrm{eV})$ of 1 from DFT calculations.

further evidence that the high volatility of these triazenide precursors is due to a large amount of electrostatic repulsion forces in solid state. The crystal structure of $\mathbf{1}$ had a high degree of disorder similar to that of $\operatorname{In}(\text { triaz })_{3}$ due to a lack of intermolecular interactions.

2.2. ALD behavior of the Ga(III) Triazenide Precursor. ALD of GaN was tested initially on $\mathrm{Si}(100)$ using a $10 \mathrm{~s}$ pulse of 1 and a $12 \mathrm{~s} \mathrm{NH}_{3}$ plasma, separated by a $10 \mathrm{~s} \mathrm{~N}_{2}$ purge, while varying the deposition temperature. These experiments showed three intervals where the growth per cycle (GPC) is constant with the temperature: 150-275, 300-350, and 375$430{ }^{\circ} \mathrm{C}$ (Figure $4 \mathrm{a}$ ). The saturation curves on $\mathrm{Si}(100)$ of the first and second temperature intervals showed saturation growth behavior with a GPC of 0.25 and $0.30 \AA /$ cycle, respectively, after a $5 \mathrm{~s}$ pulse of both 1 and $\mathrm{NH}_{3}$ plasma
(Figure 4b,c). The third temperature interval showed saturation growth behavior with a GPC of $0.70 \AA$ /cycle after a $10 \mathrm{~s}$ pulse of 1 and $5 \mathrm{~s}$ of $\mathrm{NH}_{3}$ plasma (Figure $4 \mathrm{~d}$ ). These results indicate self-limiting surface chemistry for 1 and $\mathrm{NH}_{3}$ plasma in all three temperature intervals. The GPC of interval II is similar to that reported for high-quality GaN by ALD using $\mathrm{GaMe}_{3}$ and $\mathrm{NH}_{3}$ plasma (0.26 $\AA$ GPC), whereas the GPC of interval III is nearly three times higher. ${ }^{16}$ However, the GPC of intervals II and III are lower than that reported for $\mathrm{GaN}$ by ALD using $\mathrm{Ga}\left(\mathrm{NMe}_{2}\right)_{3}$ and $\mathrm{NH}_{3}$ plasma $(1.2 \AA$ GPC). ${ }^{20}$ The deposition temperature ranges of intervals II and III indicate a higher thermal stability of the deposited surface species of 1 in comparison to the previously used $\mathrm{Ga}\left(\mathrm{NMe}_{2}\right)_{3}$, which has a constant GPC over a temperature range of 130$250{ }^{\circ} \mathrm{C}$. A linear growth trend was observed when all the parameters were kept constant upon increasing ALD cycles at 350 and $400{ }^{\circ} \mathrm{C}$ (Figure S10a,b). Extrapolation of these linear trends to zero showed a nucleation delay on $\mathrm{Si}(100)$ of 16 and 21 cycles for 350 and $400{ }^{\circ} \mathrm{C}$, respectively.

2.3. Thermal Properties of the $\mathrm{Ga}$ (III) Triazenide Precursor. Two temperature intervals with self-limiting growth behavior were observed when depositing InN using the previously mentioned $\operatorname{In}(\text { triaz })_{3} \cdot{ }^{25}$ Nevertheless, the presence of multiple temperature intervals with self-limiting growth behavior is still highly unexpected in ALD. Differential scanning calorimetry (DSC) analysis of $\mathbf{1}$ showed an endothermic event with a peak between 130 and $140{ }^{\circ} \mathrm{C}$ and two exothermic events, a sharp peak between 160 and $180^{\circ} \mathrm{C}$ and a broad peak between 200 and $280{ }^{\circ} \mathrm{C}$ (Figure S4). The onset temperature of the first exothermic event falls within the volatilization temperature range observed in TGA (155-225 ${ }^{\circ} \mathrm{C}$ ), which could indicate decomposition and volatilization occurring simultaneously. Heating of $\mathbf{1}$ in the solid state to 180 ${ }^{\circ} \mathrm{C}$ for $16 \mathrm{~h}$ showed no discoloration of the sample and no decomposition by ${ }^{1} \mathrm{H}$ NMR analysis. This result suggests that the first exothermic event does not correspond to a decomposition pathway. The spike in the GPC between 350 and $375{ }^{\circ} \mathrm{C}$ is slightly higher in temperature than the second broad exothermic event between 200 and $280{ }^{\circ} \mathrm{C}$. Heating of 1 in solution $\left(200-215^{\circ} \mathrm{C}\right.$, Figure S5) and solid $\left(220^{\circ} \mathrm{C}\right.$, Figure S6) states gave an unidentifiable white or brown solid, respectively, confirming the second exothermic peak in the DSC analysis as a decomposition event. This is a strong indication that $\mathbf{1}$ decomposes in the gas-phase inside the deposition chamber to a more volatile and reactive species at approximately $350{ }^{\circ} \mathrm{C}$. Similar behavior was observed by In(triaz) $)_{3}$ when depositing InN by $\mathrm{ALD}^{25}$ The thermal decomposition of $\mathbf{1}$ was studied by DFT calculations at 350 ${ }^{\circ} \mathrm{C}$, which shows a similar decomposition pathway to $\operatorname{In}(\text { triaz })_{3}$, although with a small energy difference (Tables S5-S8; Figures S7-S9).

2.4. GaN Film Characterization. The films deposited on $\mathrm{Si}(100)$ in temperature interval I were X-ray amorphous (Figure S11a,b), while intervals II and III gave crystalline hexagonal wurtzite $\mathrm{GaN}$ with a preferred orientation along the $c$-axis (Figure S11c,d). The small difference in GPC of intervals I and II could be explained by the change from amorphous to crystalline state. Deposition on $4 \mathrm{H}-\mathrm{SiC}$ (0001), which is more suitable than $\mathrm{Si}(100)$ in terms of lattice mismatch, ${ }^{26}$ at 350 and $400{ }^{\circ} \mathrm{C}$ both rendered epitaxial wurtzite $\mathrm{GaN}$. The $\theta-2 \theta$ X-ray diffraction (XRD) measurement shows GaN peaks corresponding to the (0002) and (0004) planes, indicating growth along the $c$-axis (Figures 5a and S12a). Grazing incidence XRD 

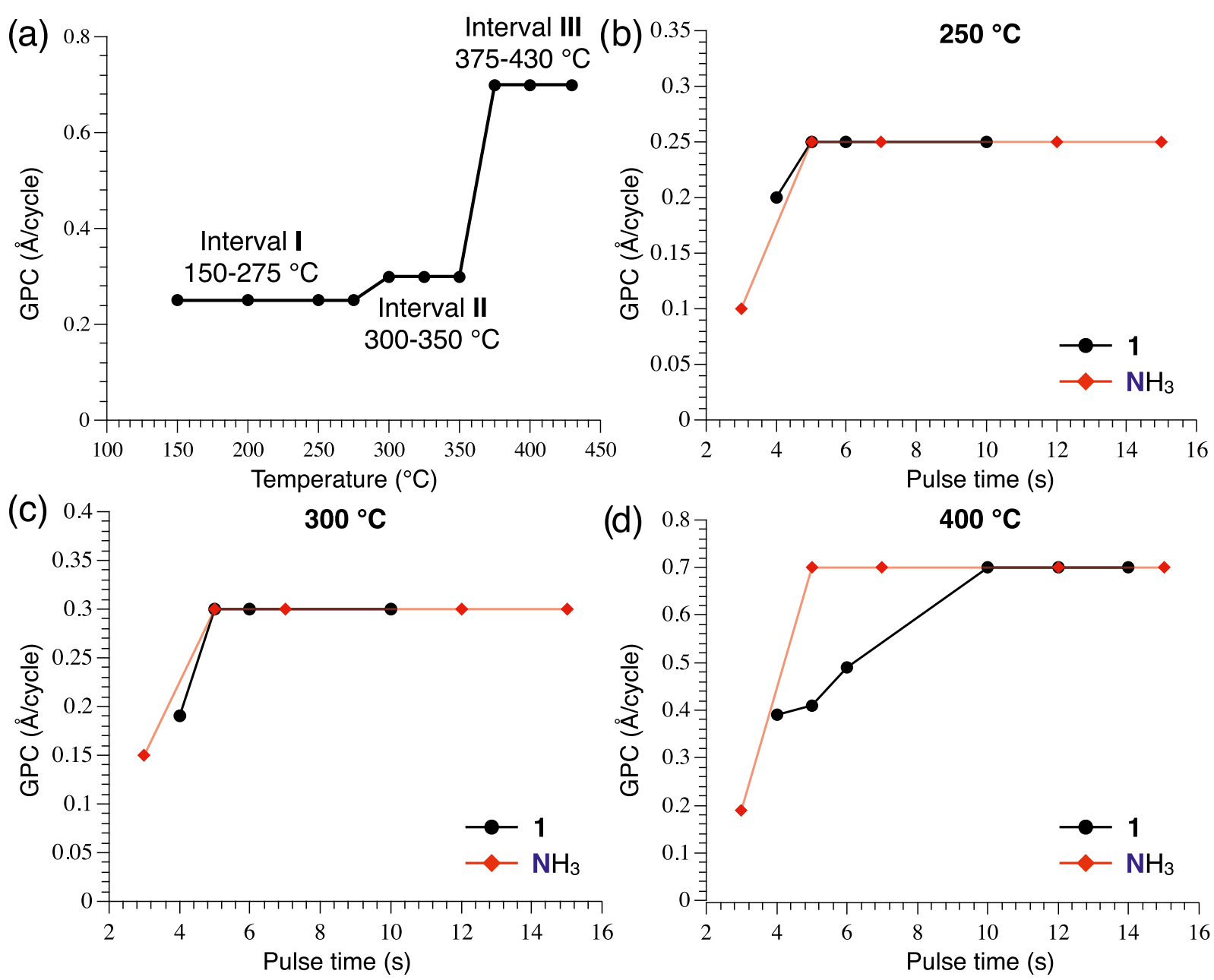

Figure 4. (a) Growth dependence on process temperature using a $10 \mathrm{~s}$ pulse of 1 and 12 s pulse of $\mathrm{NH}_{3}$ plasma on $\mathrm{Si}(100)$. The GPC behavior of 1 and $\mathrm{NH}_{3}$ plasma pulses deposited at (b) 250 , (c) 300 , and (d) $400{ }^{\circ} \mathrm{C}$ on $\mathrm{Si}(100$ ). The film thickness for all films was determined using X-ray reflectometry (XRR). The black circles are for 1 and the red diamonds are for the $\mathrm{NH}_{3}$ plasma.

(GIXRD) showed no peaks, indicating no tilted grains (Figure $\mathrm{S} 12 \mathrm{~b}, \mathrm{c})$. In-depth XRD analysis was used to investigate inplane grain orientation and the crystal relationship between the film and the substrate (Figures 5b,c; S12d). Both the Ga(1013) and $\mathrm{SiC}(10-12)$ planes showed six poles each, corresponding to the $\mathrm{GaN}$ film and $4 \mathrm{H}-\mathrm{SiC}$ substrate, respectively. This is expected for an epitaxially grown hexagonal film on a hexagonal substrate due to their six-fold symmetry. The $\theta-2 \theta$ XRD, GIXRD, and in-plane measurements show that each GaN hexagon grows epitaxially on a $4 \mathrm{H}-\mathrm{SiC}$ hexagon with no in-plane rotation, resulting in relations $\mathrm{GaN}(0002) \| \mathrm{SiC}(0004)$ and $\mathrm{GaN}(10-13) \| \mathrm{SiC}(10-$ 12). This confirms the epitaxial relationship between the $\mathrm{GaN}$ film and the $4 \mathrm{H}-\mathrm{SiC}$ substrate for films deposited at both 350 and $400{ }^{\circ} \mathrm{C}$. In addition, it shows that 1 can render epitaxial $\mathrm{GaN}$ directly on $4 \mathrm{H}-\mathrm{SiC}$ without the need for an AlN nucleation buffer layer. Top-view scanning electron microscopy (SEM) images of the GaN films on $4 \mathrm{H}-\mathrm{SiC}$ at 350 and $400{ }^{\circ} \mathrm{C}$ both showed a smooth surface (Figures 5d, S13d). Rutherford backscattering spectroscopy (RBS) and time-offlight elastic recoil detection (ToF-ERDA) analyses were used to determine the elemental composition of the films. The films deposited at $350{ }^{\circ} \mathrm{C}$ (interval II) gave a composition of 48.8 at. $\% \mathrm{Ga}, 46.4$ at. $\% \mathrm{~N}, 3.0$ at. $\% \mathrm{O}, 1.8$ at. $\% \mathrm{H}$, and no detectable $\mathrm{C}$, showing a near stoichiometric $\mathrm{Ga} / \mathrm{N}$ ratio of 1.05 . The films deposited at $400{ }^{\circ} \mathrm{C}$ (interval III) gave a composition of 44.0 at. $\% \mathrm{Ga}, 49.1$ at. $\% \mathrm{~N}, 6.0$ at. $\% \mathrm{O}, 0.5$ at. $\% \mathrm{H}$, and 0.4 at. $\% \mathrm{C}$, showing a $\mathrm{Ga} / \mathrm{N}$ ratio of 0.90 . The low $\mathrm{C}$ impurities in these films suggest that $\mathbf{1}$ has superior deposition chemistry over a larger temperature range in comparison to the previously used $\mathrm{GaMe}_{3},{ }^{13,15-18} \mathrm{GaEt}_{3},{ }^{14,15,17}$ and $\mathrm{Ga}\left(\mathrm{NMe}_{2}\right)_{3}{ }^{20}$ literature precursors. The oxygen impurities in these films are of a similar level to the lowest values reported using $\mathrm{GaMe}_{3}{ }^{16}$ or $\mathrm{Ga}\left(\mathrm{NMe}_{2}\right)_{3}{ }^{20}$ with $\mathrm{NH}_{3}$ plasma. The lack of oxygen atoms in $\mathbf{1}$ and $\mathrm{NH}_{3}$ clearly shows that the source of oxygen impurities is not precursor-related. The sources could include residual oxygen and moisture in the ALD reaction chamber, etching of the inductively coupled plasma quartz tube, or post-deposition oxidation of $\mathrm{GaN}$ films ( $\mathrm{GaN}, \Delta_{\mathrm{f}} \mathrm{G}^{\circ}=-78 \mathrm{~kJ} / \mathrm{mol}^{-1} ; \mathrm{Ga}_{2} \mathrm{O}_{3}$, $\left.\Delta_{\mathrm{f}} G^{\circ}=-998 \mathrm{~kJ} / \mathrm{mol}^{-1}\right){ }^{27}$ The higher tolerance of 1 to oxygen and moisture over $\mathrm{GaMe}_{3}$ and $\mathrm{Ga}\left(\mathrm{NMe}_{2}\right)_{3}$ gives great promise to completely removing the oxygen impurities. We believe that the implementation of a load-lock antechamber with a high vacuum system to the ALD instrument and an oxygen-free environment for creating a plasma would dramatically decrease the oxygen impurities in the GaN films deposited by this new Ga triazenide precursor.

The microstructure of the GaN film deposited at $350{ }^{\circ} \mathrm{C}$ on $4 \mathrm{H}-\mathrm{SiC}$ was characterized by high-resolution scanning transmission electron microscopy (HR-STEM) with high- 
(a)<smiles>[Mg]O[Mg][Mg]</smiles>

$\mathrm{SiC}$ (0004)

GaN . (0002)

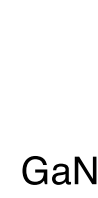

(0004)

(c)
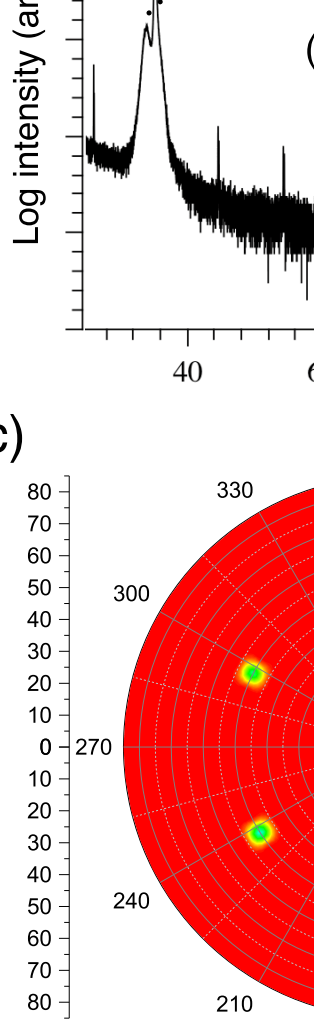

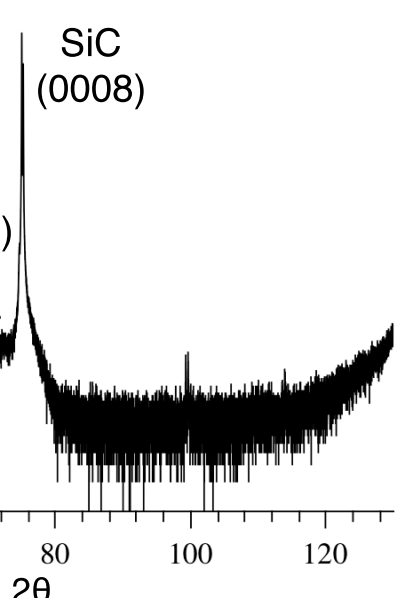

(b)

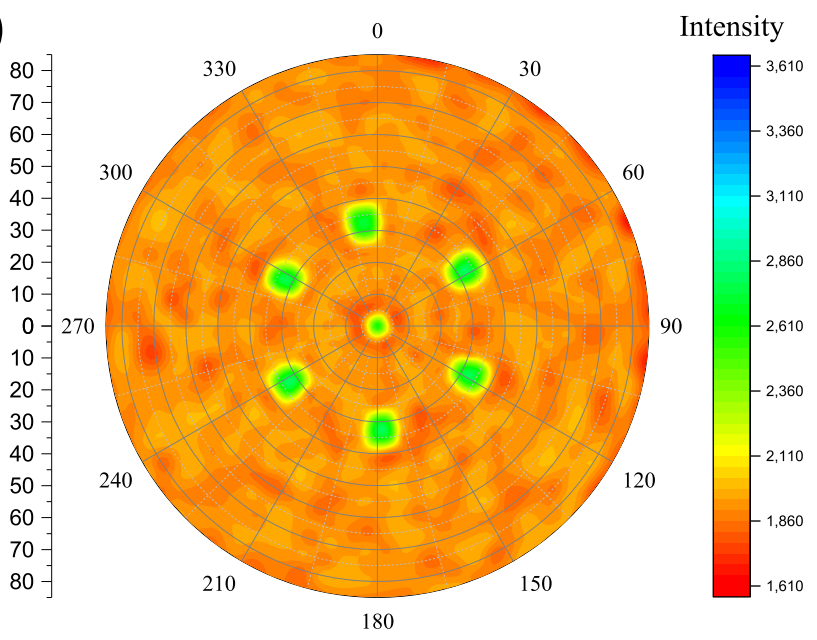

$2 \theta$

0

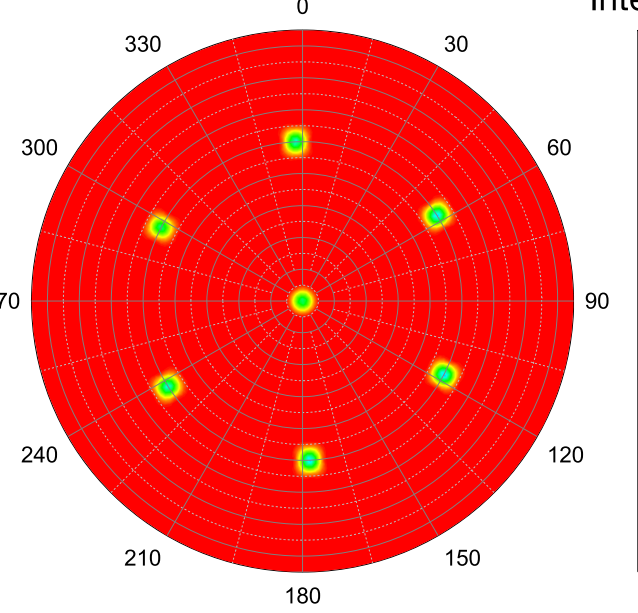

Intensity

(d)

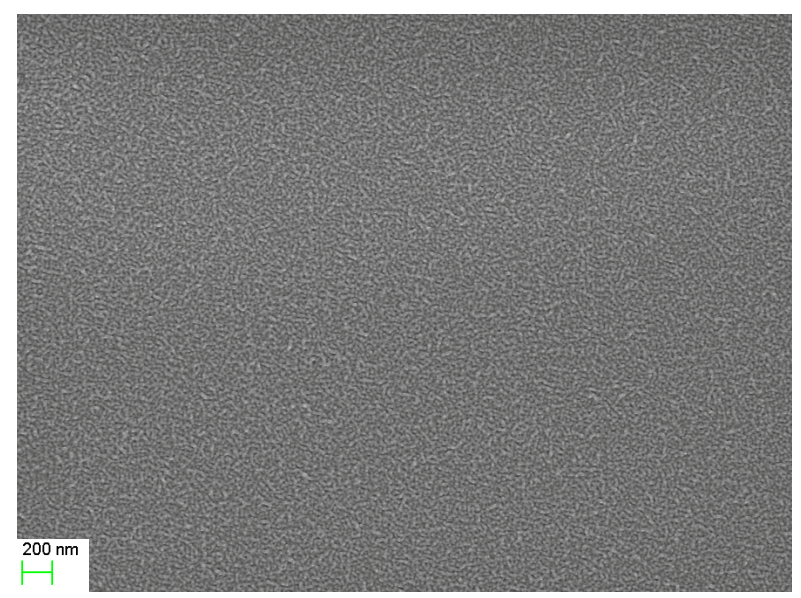

Figure 5. (a) $\mathrm{XRD}$ of $\mathrm{GaN}$ on $4 \mathrm{H}-\mathrm{SiC}(0001)$ deposited at $350{ }^{\circ} \mathrm{C}$ with a thickness of approximately $30 \mathrm{~nm}$ showing epitaxial GaN along the $c$ axis. (b) Pole figure of the $\mathrm{GaN}(10-13)$ plane showing 6 poles corresponding to the GaN substrate. (c) Pole figure of the SiC(10-12) plane showing 6 poles corresponding to the $\mathrm{SiC}$ substrate. The thickness of the GaN film used for pole figure analysis was approximately $30 \mathrm{~nm}$. (d) Topview $\mathrm{SEM}$ of $\mathrm{GaN}$ on $4 \mathrm{H}-\mathrm{SiC}$ deposited at $350{ }^{\circ} \mathrm{C}$ with a thickness of approximately $30 \mathrm{~nm}$.

angle annular dark-field (HAADF) imaging (Figure 6). The film was observed to be smooth (Figure 6a), and the heteroepitaxial relationship between $\mathrm{GaN}$ and $4 \mathrm{H}-\mathrm{SiC}$ substrates can be visualized by the fast Fourier transform (FFT) patterns (Figure 6a, inset). A sharp interface transition was observed, indicating no amorphous interlayer between the $\mathrm{GaN}$ film and the substrate (Figure $6 \mathrm{~b}$ ). The stacking of GaN layers within the crystal is more regular at the substrate interface (Figure 6b) in comparison to the top of the film (Figure 6c), without signs of a significant lattice curvature. In addition, the angular dispersion of the FFT patterns of this film is far less pronounced and implies a notably improved stacking coherence of the GaN crystal and is in contrast to our previously reported ALD of $\mathrm{GaN}$ with the $\mathrm{Ga}\left(\mathrm{NMe}_{2}\right)_{3}{ }^{20}$ The XRD rocking curve (XRC) on the GaN film deposited at 350 ${ }^{\circ} \mathrm{C}$ showed the full width half maximum for the (0002) plane was $280 \operatorname{arcsec}\left(0.07754^{\circ}\right)$ (Figure S14). This value indicates lower stress and higher crystalline quality for the deposited film in comparison to our previously reported GaN by ALD using $\mathrm{Ga}\left(\mathrm{NMe}_{2}\right)_{3}(523$ arcsec $)$ and high-temperature metal organic CVD (MOCVD) GaN deposited on either SiC $(607 \mathrm{arcsec})^{8}$ using an AlN seed layer or directly onto sapphire (310 arcsec).${ }^{10}$ The smooth surface, sharp interface, and low stress in the film highlight the quality of the GaN film deposited when using this new $\mathrm{Ga}(\mathrm{III})$ triazenide precursor.

An absorption measurement was undertaken to obtain the optical properties of the GaN film deposited at $350{ }^{\circ} \mathrm{C}$. A Tauc plot was constructed to express the optical band gap for the direct band gap material (eq 1). Using the linear section of the Tauc plot, the optical band gap was extrapolated and found to be approximately $3.41 \mathrm{eV}$ (Figure 7a). This is very close to the reported value for single-crystalline $\mathrm{GaN}$ of $3.40 \mathrm{eV}$. $^{5}$

$$
\alpha h \nu=A\left(h \nu-E_{\mathrm{g}}\right)^{1 / 2}
$$

$\mathrm{X}$-ray photoelectron spectroscopy (XPS) was used to investigate the valence band (VB) of the GaN film (Figure $7 \mathrm{~b}$ ). The intersection between the linear fit of the slope and baseline of the spectrum revealed the $\mathrm{VB}$ maximum at approximately $1.90 \mathrm{eV}$. This indicates the Fermi level $\left(E_{\mathrm{F}}\right)$ is located slightly toward the conduction band in relation to the VB (Figure 7c). This result shows the deposited GaN film is unintentionally n-type-doped, which is expected due to the $\mathrm{O}$ impurities and potential $\mathrm{N}$ vacancies in the film. ${ }^{28-30} \mathrm{In}$ addition, this result is close to the $E_{\mathrm{F}}$ value of nondoped $\mathrm{GaN}$ $(1.70 \mathrm{eV})$ and is lower than our previously reported ALD of 


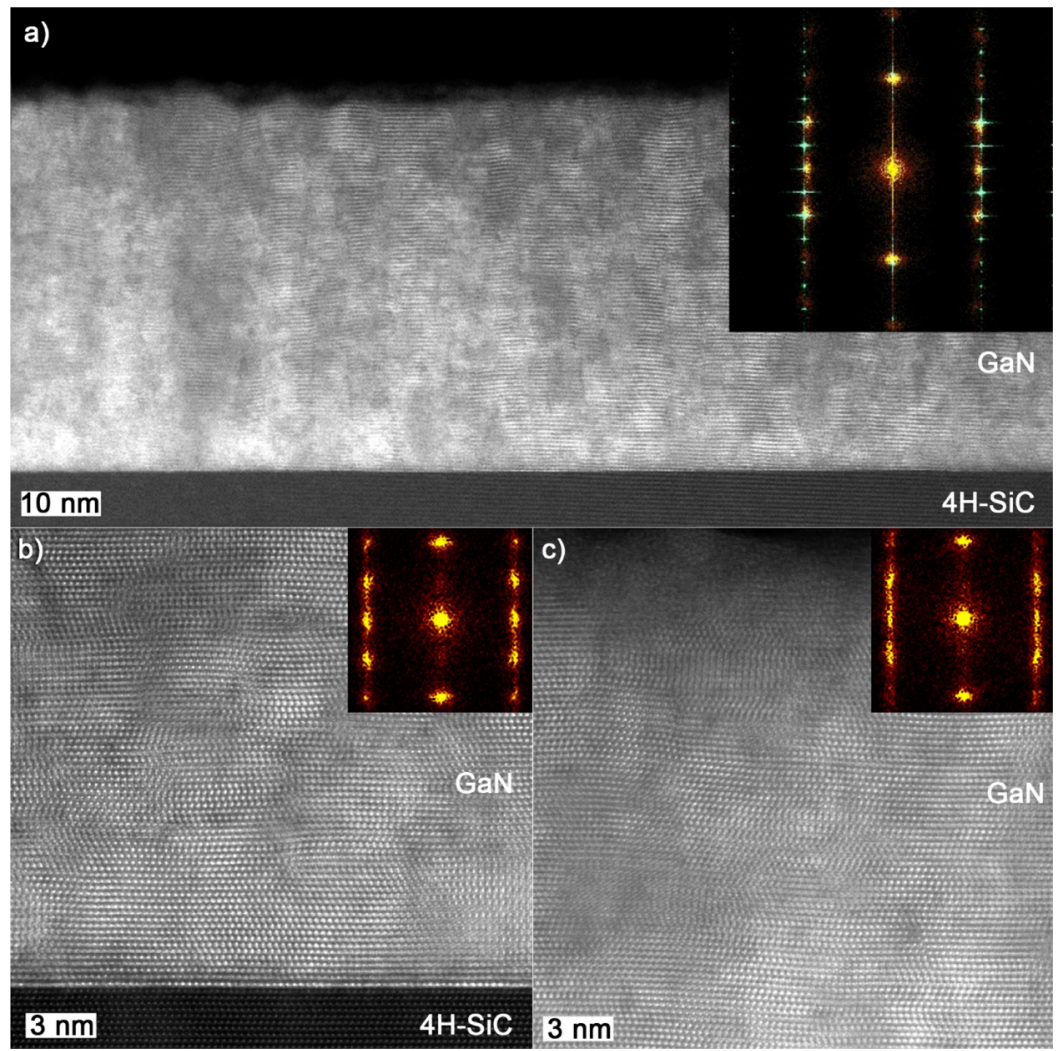

Figure 6. (a) Overview of the STEM-HAADF image from the GaN film with a thickness of approximately $60 \mathrm{~nm}$ on $4 \mathrm{H}-\mathrm{SiC}$. (b) HR-STEMHAADF image of the film-substrate interface and (c) top part of the film. The FFT patterns are shown as insets in $(a-c)$ with orange as GaN and cyan as the $4 \mathrm{H}-\mathrm{SiC}$ substrate.

$\mathrm{GaN}(2.20 \mathrm{eV}){ }^{20}$ which could be due to the lower amount of $\mathrm{C}$ impurities in the film. Photoluminescence (PL) spectroscopy was used to measure the emission properties of the $\mathrm{GaN}$ film at room temperature (Figure $7 \mathrm{~d}$ ). Three emission bands at $2.9,2.4$, and $1.8 \mathrm{eV}$ were observed and assigned as the blue line $(B L)$, green line $(\mathrm{GL})$, and red line (RL) bands, respectively. The BL and GL bands are commonly displayed in high-quality unintentionally doped $\mathrm{GaN}$ made by MOCVD or hydride vapor phase epitaxy (HVPE). ${ }^{31}$ The RL band is less common and is found in GaN grown under Ga-rich conditions. ${ }^{31}$ Next, the GaN film was analyzed by ellipsometry and the data was fitted using the Kramer-Kronig model (Figure S15). The refractive index was 2.25 at $632 \mathrm{~nm}$, which is slightly higher than that of previously reported ALD of GaN using $\mathrm{GaMe}_{3}{ }^{16}$ (2.17) but still lower than the literature value of singlecrystalline $\mathrm{GaN}(2.38)$. $^{32}$

\section{CONCLUSIONS}

In conclusion, we have developed a new highly volatile $\mathrm{Ga}$ (III) precursor for the deposition of high-quality GaN films. This new $\mathrm{Ga}(\mathrm{III})$ triazenide was the first hexacoordinated $\mathrm{Ga}-\mathrm{N}$ bonded precursor used in a vapor deposition process. TGA of 1 showed it underwent single-step volatilization between 150 and $220^{\circ} \mathrm{C}$ with negligible residual mass, while heating studies revealed its decomposition point at $\sim 215-220{ }^{\circ} \mathrm{C}$. The GaN films deposited at $350{ }^{\circ} \mathrm{C}$ were epitaxial on $4 \mathrm{H}-\mathrm{SiC}$, without the need for an AlN buffer layer, and a near stoichiometric $\mathrm{Ga}$ / $\mathrm{N}$ ratio with no detectable $\mathrm{C}$ impurities. This result is significant as the lack of $\mathrm{C}$ impurities shows the vastly superior deposition chemistry of this new precursor over the currently used literature precursors. The quality of the deposited GaN was further highlighted by electron microstructure analysis, which showed the film was smooth with a sharp interface between the substrate and film. The band gap of these films was $3.41 \mathrm{eV}$ with the Fermi level at $1.90 \mathrm{eV}$, showing the $\mathrm{GaN}$ films were unintentionally n-type-doped. This new triazenide precursor opens the door to deposit high-quality GaN on temperature-sensitive materials for semiconductor applications, which has previously been hindered by a lack of suitable $\mathrm{Ga}$ (III) precursors. The development of new ALD processes with this Ga triazenide precursor is currently underway.

\section{EXPERIMENTAL SECTION}

4.1. General Experimental Procedures. Caution! As catenated nitrogen compounds are known to be associated with explosive hazards, isopropylazide and compound $\mathbf{1}$ are possible explosive energetic materials. Although we have not experienced any difficulties or problems in the synthesis, characterization, sublimation, and handling of compound 1, its energetic properties have not been investigated and are therefore unknown. We therefore highly recommend that all appropriate standard safety precautions for handling explosive materials (safety glasses, face shield, blast shield, leather gloves, polymer apron, and ear protection) be used at all times when working with isopropylazide and compound $\mathbf{1}$. All reactions and manipulations were carried out under an $\mathrm{N}_{2}$ atmosphere, both on a Schlenk line using Schlenk air-free techniques and in a GS GloveboxSystemtechnik glovebox. All anhydrous solvents were purchased from Sigma-Aldrich and further dried with $4 \AA$ molecular sieves. $\mathrm{GaCl}_{3}$ (99.99\%) was purchased from ACROS-Organics and isopropyllithium from Sigma-Aldrich, and both were used without further purification. Isopropylazide was synthesized according to the literature procedure. ${ }^{33}$ All NMR spectra were measured with an Oxford Varian 300 $\mathrm{MHz}$ spectrometer. The solvent peaks were used as an internal standard for the ${ }^{1} \mathrm{H}$ NMR $(300 \mathrm{MHz})$ and ${ }^{13} \mathrm{C}\left\{{ }^{1} \mathrm{H}\right\} \mathrm{NMR}(75 \mathrm{MHz})$ 
(a)

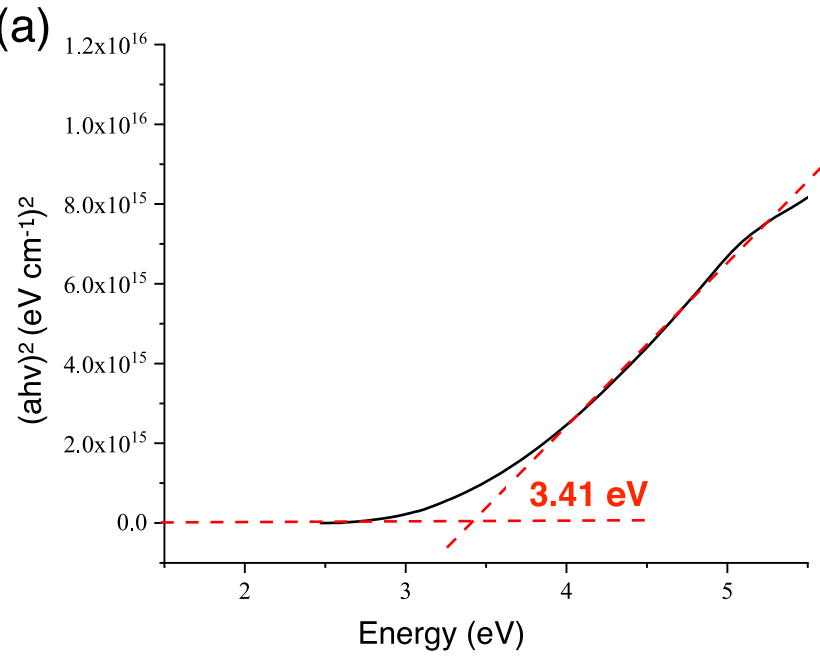

(c)

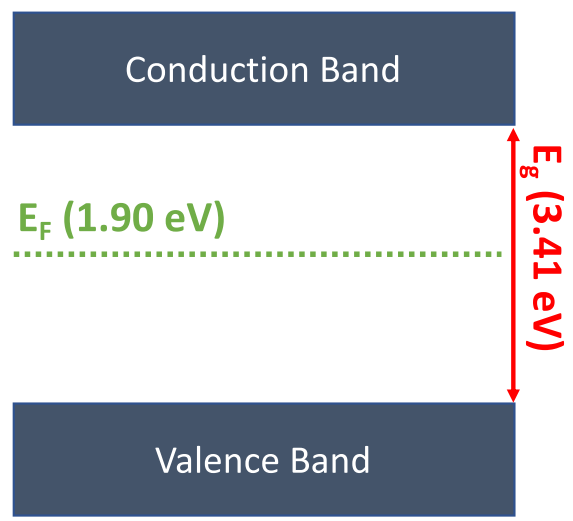

(b)
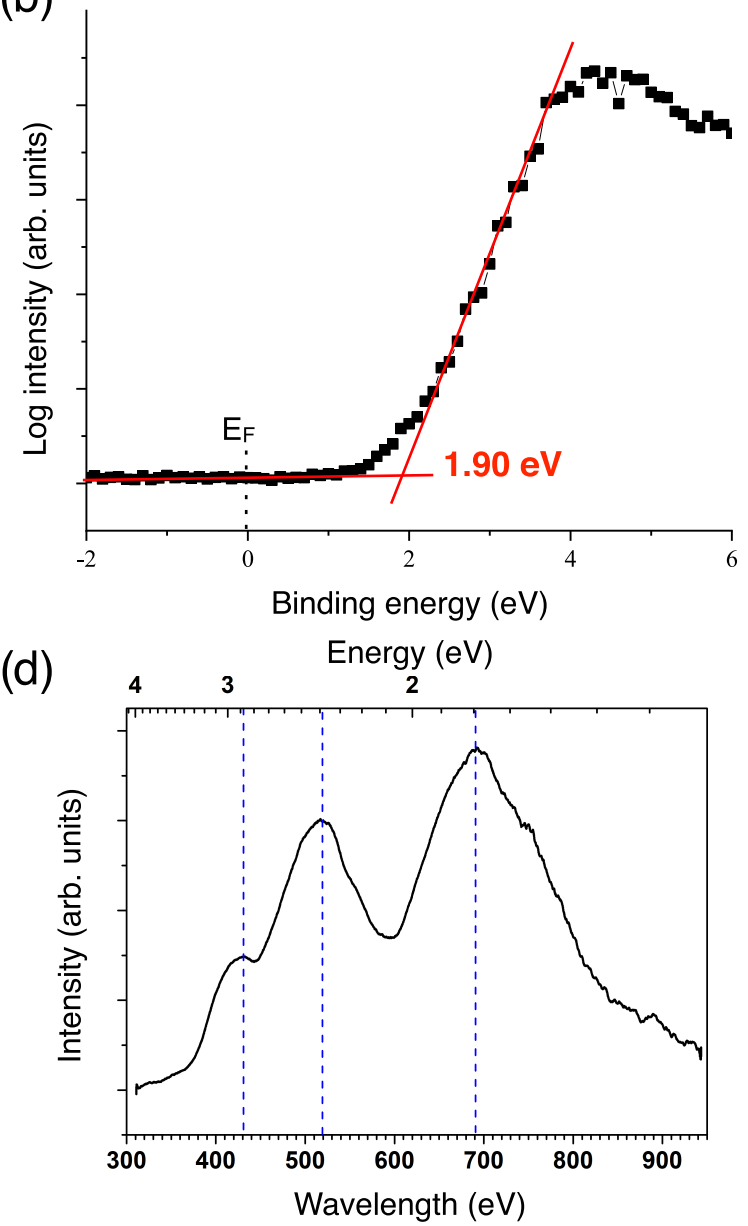

Figure 7. (a) Tauc plot constructed from the absorption measurement showing a band gap of $3.41 \mathrm{eV}$ for the deposited GaN film with a thickness of approximately $30 \mathrm{~nm}$. (b) VB spectrum obtained from XPS for the deposited GaN film with a thickness of approximately $30 \mathrm{~nm}$ showing the VB maxima lies $1.90 \mathrm{eV}$ below the Fermi level. (c) Schematic band structure with the measured band gap and Fermi level. (d) Room temperature PL of the GaN films deposited at $350{ }^{\circ} \mathrm{C}$ on $\mathrm{Si}(100)$ with a thickness of approximately $30 \mathrm{~nm}$.

spectra. The melting point was determined in a capillary sealed under $\mathrm{N}_{2}$ with a Stuart SMP10 melting point apparatus and is uncorrected. Elemental analysis was performed by Mikroanalytisches Laboratorium Kolbe, Germany.

4.2. Synthesis of Tris(1,3-diisopropyltriazenide)gallium(III) 1. To a solution of isopropylazide ${ }^{33}(7.51 \mathrm{~g}, 88.2 \mathrm{mmol})$ in $\mathrm{Et}_{2} \mathrm{O}(150$ $\mathrm{mL})$ at $-78{ }^{\circ} \mathrm{C}$ was added isopropyl lithium $(0.7 \mathrm{M}$ in pentane, 126.0 $\mathrm{mL}, 88.2 \mathrm{mmol}$ ). The reaction mixture was stirred for $30 \mathrm{~min}$ and then allowed to warm up to room temperature for $1 \mathrm{~h}$. This solution was then added to a $-78{ }^{\circ} \mathrm{C}$ solution of $\mathrm{GaCl}_{3}(5.17 \mathrm{~g}, 29.4 \mathrm{mmol})$ in a 9:1 mixture of $\mathrm{THF} / n$-hexane $(170 \mathrm{~mL})^{*}$ via cannula, and the mixture was stirred at this temperature for $2 \mathrm{~h}$. The reaction was warmed very slowly to room temperature and stirred for $16 \mathrm{~h}$. The reaction mixture was concentrated under reduced pressure, and the resulting residue was dissolved in $n$-hexane, filtered through a pad of Celite, and concentrated under reduced pressure to give a dark-orange semisolid. The crude was purified by either recrystallization from $\mathrm{Et}_{2} \mathrm{O} / \mathrm{MeCN}$ or sublimation at $90{ }^{\circ} \mathrm{C}(0.5 \mathrm{mbar})$ to give compound $\mathbf{1}$ as a solid $(8.28 \mathrm{~g}, 62 \%)$. ${ }^{*}$ The solution of $\mathrm{GaCl}_{3}$ in a 9:1 mixture of $\mathrm{THF} / n$-hexane was prepared by first suspending the $\mathrm{GaCl}_{3}$ in $n$ hexane $(20 \mathrm{~mL})$ and then slowly adding cold THF $(150 \mathrm{~mL})$.

1: Colorless solid, decomp. 228-230 ${ }^{\circ} \mathrm{C}$. ${ }^{1} \mathrm{H}$ NMR $(300 \mathrm{MHz}$, $\left.\mathrm{C}_{6} \mathrm{D}_{6}\right): \delta 1.26\left(\mathrm{~d}, J=6.0 \mathrm{~Hz}, 36 \mathrm{H}, \mathrm{CH}_{3}\right), 3.96$ (sept, $J=6.0 \mathrm{~Hz}, 6 \mathrm{H}$, $\mathrm{CH}) .{ }^{13} \mathrm{C}\left\{{ }^{1} \mathrm{H}\right\} \mathrm{NMR}\left(75 \mathrm{MHz}, \mathrm{C}_{6} \mathrm{D}_{6}\right): \delta 23.7\left(\mathrm{~s}, \mathrm{CH}_{3}\right), 53.0(\mathrm{~s}, \mathrm{CH})$. Anal. Calcd for $\mathrm{C}_{18} \mathrm{H}_{42} \mathrm{GaN}_{9}$ : C, 47.59\%; H, 9.32\%; N, $27.75 \%$. Found: C, $47.54 \%$; H, 9.30\%; N, 27.72\%.
4.3. X-ray Crystallographic Analysis. Colorless single crystals were obtained by recrystallization from $\mathrm{Et}_{2} \mathrm{O} / \mathrm{MeCN}$ at $-35^{\circ} \mathrm{C}$ for $\mathbf{1}$. The single crystals were used for XRD data collection on a Bruker D8 SMART Apex-II diffractometer using graphite-monochromated Mo $\mathrm{K} \alpha$ radiation $\left(\lambda_{\mathrm{F}}=0.71073 \AA\right)$. All data were collected in the hemisphere with over $95 \%$ completeness to $2 \theta<50.05^{\circ}$. The structures were solved by direct methods. The coordinates of metal atoms were determined from the initial solutions, and the $\mathrm{N}$ and $\mathrm{C}$ atoms were located in the subsequent differential Fourier syntheses. All non-hydrogen atoms were refined first in isotropic and then in anisotropic approximation using Bruker SHELXTL software. Additional crystal data are available at the Cambridge Crystallographic Data Centre, deposition no. CCDC 2040929.

4.4. Thermogravimetric Analysis. Volatilization and vapor pressure curves were collected using a TA Instruments thermogravimetric analysis Q500 tool inside an $\mathrm{N}_{2}$-filled glovebox. The ramp experiment of $\mathbf{1}$ was undertaken in tared platinum pans loaded with 10,20 , and $30 \mathrm{mg}$ of $\mathbf{1}$ for low, medium, and high mass volatilization experiments, respectively. The furnace was heated at a rate of $10{ }^{\circ} \mathrm{C} /$ min to $500{ }^{\circ} \mathrm{C}$ with a maintained $\mathrm{N}_{2}$ flow rate of $60 \mathrm{sccm}$.

4.5. Differential Scanning Calorimetry. The DSC measurement for 1 was performed on a TA Instruments DSC Q10 tool. Approximately, $0.2 \mathrm{mg}$ of $\mathbf{1}$ was loaded into a sealed aluminum pan in an $\mathrm{N}_{2}$-filled glovebox. The sample of $\mathbf{1}$ and a blank reference pan was heated at a rate of $10^{\circ} \mathrm{C} / \mathrm{min}$ to $400{ }^{\circ} \mathrm{C}$.

4.6. Quantum Chemical Computations. All quantum chemical computations were performed using Gaussian 16 software. ${ }^{34}$ 
Structural optimization and harmonic normal mode vibrational calculations were done using the hybrid DFT method B3LYP ${ }^{35,36}$ together with Grimme's version 3 dispersion correction ${ }^{37}$ and def2TZVP ${ }^{38,39}$ basis set. The decomposition path was investigated by searching for possible stable structures as well as finding transition states connecting these structures. Minima were confirmed to have no imaginary frequencies, while transition states were verified to have one imaginary frequency, lying along the reaction path.

4.7. Film Deposition. A hot-wall Picosun R-200 was used for the deposition of $\mathrm{GaN}$, which was equipped with a Litmas remote plasma source. The tool operated at 4 mbar with a continuous flow of high purity $\mathrm{N}_{2}$ (99.999\%) into the chamber, which was also used as the purge gas. The system was equipped with a traditional stainless steel precursor container (bubbler), albeit without a dip tube for the incoming carrier gas. The system was baked at $450{ }^{\circ} \mathrm{C}$ for $2 \mathrm{~h}$ with a $300 \mathrm{sccm}$ flow of $\mathrm{N}_{2}$ to remove traces of $\mathrm{H}_{2} \mathrm{O}$ and $\mathrm{O}_{2}$ in the deposition chamber due to its exposure to the atmosphere during substrate exchange. In a $\mathrm{N}_{2}$-filled glovebox, approximately $800 \mathrm{mg}$ of precursor 1 was placed in a glass vial, which then was placed in the stainless steel container and then assembled on the ALD tool. Caution! The bubbler must not be overfilled with the multigram scale of precursor 1 due to possible explosion risk. The optimal temperature for the bubbler in order to obtain high enough vapor pressure to saturate the substrate and obtain optimal growth was 130 ${ }^{\circ} \mathrm{C}$. Approximately $800 \mathrm{mg}$ of the precursor was enough for 1000 cycles and the amount of precursor required increased linearly with the number of cycles. A gas mixture containing a 100/75 ratio of $\operatorname{Ar}(99.9997 \%)$ and $\mathrm{NH}_{3}$ (99.999\%), that were both further dried using a getter filter, was used for the $\mathrm{NH}_{3}$ plasma with a $2800 \mathrm{~W}$ plasma power and was located approximately $75 \mathrm{~cm}$ above the substrate. ${ }^{25,40}$ Unless otherwise stated, a $12 \mathrm{~s} \mathrm{NH}_{3}$ pulse was used, followed by a $10 \mathrm{~s}$ purge. The $\mathrm{Si}(100)$ and $4 \mathrm{H}-\mathrm{SiC}$ substrates were cut into $15 \times 15 \mathrm{~mm}^{2}$ pieces, and films were deposited on them. Prior to deposition, the $4 \mathrm{H}-\mathrm{SiC}$ pieces were cleaned with RCA-1 [1:1:5 solution of $\mathrm{H}_{2} \mathrm{O}_{2}(30 \%), \mathrm{NH}_{3}(25 \%)$, and $\mathrm{H}_{2} \mathrm{O}$ ] and RCA-2 [1:1:6 solution of $\mathrm{H}_{2} \mathrm{O}_{2}(30 \%), \mathrm{HCl}(37 \%)$, and $\mathrm{H}_{2} \mathrm{O}$ ] solutions to remove organic and inorganic contaminants. The $\mathrm{Si}(100)$ pieces were used without further ex situ cleaning.

4.8. Film Characterization. Film thickness (XRR) and film crystallinity $(\theta-2 \theta)$ were measured using PANalytical X'Pert PRO with a $\mathrm{Cu}$-anode tube and Bragg-Brentano $\mathrm{HD}$ optics. To analyze the thickness, the software PANalytical X'Pert reflectivity and a twolayer model were used to fit the data, GaN/substrate. PANalytical EMPYREAN MRD XRD with a $\mathrm{Cu}$-anode $\mathrm{X}$-ray tube and the fiveaxis $(x-y-z-v-u)$ sample stage operating at $45 \mathrm{kV}$ and $40 \mathrm{~mA}$ were used for XRC and in GIXRD mode with a $0.5^{\circ}$ incident angle to analyze the crystallinity of the films. The pole figures and phi measurement were obtained with the same XRD equipment and operating parameters using an X-ray lens and a parallel plate collimator. The morphology of the films was examined with a LEO 1550 SEM operating at an acceleration voltage of $10 \mathrm{kV}$. The elemental composition of the films was obtained using RBS and ToFERDA. The measurements were carried out in a 5 MV NEC-5SDH-2 pelletron tandem accelerator. The RBS measurements employed 2 $\mathrm{MeV}{ }^{4} \mathrm{He}^{+}$ions and detected within a scattering angle of $170^{\circ}$. Two different geometries, azimuth angles of $5^{\circ}+$ tilt angle $2^{\circ}$ and $40^{\circ}+$ tilt angle $2^{\circ}$, were chosen in order to minimize channeling effects. In addition, more suppression of the probable channeling effects was undertaken by multiple small random-angular movements around the equilibrium angles within the range of $2^{\circ}$. RBS spectra were fitted by SIMNRA 7.02 code $^{41}$ with a $\sim 2 \%$ statistic uncertainty to determine elemental compositions. In ToF-ERDA, recoils were detected at the $45^{\circ}$ angle between the primary beam and a ToF-E detector telescope in a gas ionization chamber (GIC) using a $36 \mathrm{MeV}^{127} \mathrm{I}^{8+}$ beam incident at $67.5^{\circ}$ with respect to the sample surface normal. The ToFE detector telescope consists of two circular carbon foils with 8 and 5 $\mu \mathrm{g} / \mathrm{cm}^{2}$ thicknesses, $6 \mathrm{~mm}$ radius, a $0.05 \mathrm{msr}$ solid angle $(\Delta \Omega)$, and a flight distance of $425 \mathrm{~mm}$ between the foils. Utilizing a ToF-GIC setup provides a system with good energy resolution and enhanced ion species separation in terms of mass and energy. ${ }^{42}$ Average elemental composition of the films was also obtained from ToFERDA time-energy coincidence spectra using two different software packages, CONTES ${ }^{43}$ and Potku. ${ }^{44}$ Systematic uncertainties of the experiment, discussed in more detail elsewhere ${ }^{45}$ in particular for light elements, were estimated to be a maximum of $5-10 \%$, whereas statistic uncertainties due to the number of experimental counts were $<2.3 \%$. However, the relative elemental concentrations were obtained with higher accuracy. ${ }^{46,47}$ The stopping power data required for both RBS and ERDA simulations were retrieved from the SRIM2013 code. $^{48}$ The cross-sectional TEM samples were prepared by the traditional sandwich approach, which includes sample cutting, gluing, polishing, and ion milling. A Gatan Precision Ion Polishing System model 691 operated at $5 \mathrm{kV}$ and $40 \mathrm{~mA}$, with an Ar ion source, was used to make the sample electron transparent. STEMHAADF imaging was performed using the Linköping double Cs corrected FEI Titan ${ }^{3}$ $60-300$ operated at $300 \mathrm{kV}$. The absorbance measurements were conducted using a custom fiber optical setup consisting of a light source (Ocean Optics DH-2000-BAL), a detector (Avantes AvaSpecDual), and a bifurcated optical fiber (Ocean Optics BIFBORO-21000). An absorption spectrum for the GaN film was collected using custom software-based LabView (National Instruments) with a $\mathrm{Si}(100)$ substrate used as a reference. Kratos AXIS Ultra DLD XPS was used to analyze the Fermi level of the film. The PL spectroscopy was conducted at room temperature using a continuous wave $266 \mathrm{~nm}$ laser as the excitation source with an output power of $60 \mathrm{~mW}$. The excitation with a continuous-wave laser operated at $266 \mathrm{~nm}$ was 4.66 $\mathrm{eV}$, which is larger than the $3.40 \mathrm{eV}$ band gap of $\mathrm{GaN}$. The laser was guided through a reflective objective to focus on the sample for excitation. The emission was collected by the same objective and then guided to the detector. The detector was a TRIAX monochrometer equipped with a $600 \mathrm{~g} / \mathrm{mm}$ grating and liquid- $\mathrm{N}_{2}$-cooled back-thinned charge-coupled device. The ellipsometry measurement was performed using a J. A. Woollam. Co. spectroscopic ellipsometer at 65, 70, and $75^{\circ}$ angles.

\section{ASSOCIATED CONTENT}

\section{(s) Supporting Information}

The Supporting Information is available free of charge at https://pubs.acs.org/doi/10.1021/acs.chemmater.1c00244.

Precursor and film characterization and computational calculation data (PDF)

Crystallographic data (CIF)

\section{AUTHOR INFORMATION}

\section{Corresponding Author}

Nathan J. O'Brien - Department of Physics, Chemistry and Biology, Linköping University, Linköping SE-58183, Sweden; ๑ orcid.org/0000-0003-3633-9674;

Email: nathan.o.brien@liu.se

\section{Authors}

Polla Rouf - Department of Physics, Chemistry and Biology, Linköping University, Linköping SE-58183, Sweden; (1) orcid.org/0000-0002-1452-4548

Rouzbeh Samii - Department of Physics, Chemistry and Biology, Linköping University, Linköping SE-58183, Sweden; (1) orcid.org/0000-0001-9380-4072

Karl Rönnby - Department of Physics, Chemistry and Biology, Linköping University, Linköping SE-58183, Sweden; (1) orcid.org/0000-0002-8066-9454

Babak Bakhit - Department of Physics, Chemistry and Biology, Linköping University, Linköping SE-58183, Sweden; 다잉.org/0000-0002-3083-7536

Sydney C. Buttera - Department of Chemistry, Carleton University, Ottawa, Ontario K1S 5B6, Canada 
Ivan Martinovic - Department of Physics, Chemistry and Biology, Linköping University, Linköping SE-58183, Sweden

Lars Ojamäe - Department of Physics, Chemistry and Biology, Linköping University, Linköping SE-58183, Sweden; (1) orcid.org/0000-0002-5341-2637

Chih-Wei Hsu - Department of Physics, Chemistry and Biology, Linköping University, Linköping SE-58183, Sweden

Justinas Palisaitis - Department of Physics, Chemistry and Biology, Linköping University, Linköping SE-58183, Sweden

Vadim Kessler - Department of Molecular Sciences, Swedish University of Agricultural Sciences, Uppsala 75007, Sweden

Henrik Pedersen - Department of Physics, Chemistry and Biology, Linköping University, Linköping SE-58183, Sweden; (1) orcid.org/0000-0002-7171-5383

Complete contact information is available at:

https://pubs.acs.org/10.1021/acs.chemmater.1c00244

\section{Author Contributions}

"P.R. and R.S. contributed equally to the manuscript.

\section{Notes}

The authors declare no competing financial interest.

\section{ACKNOWLEDGMENTS}

The authors acknowledge Seán Barry for access to TGA and DSC instruments, Erik Martinsson for help with the absorption measurements, and Steffen Richter for help with processing the ellipsometry data. This project was funded by the Swedish Foundation for Strategic Research through the project "Timeresolved low temperature CVD for III-nitrides" (SSF-RMA 15-0018) and by the Knut and Alice Wallenberg Foundation through the project "Bridging the $\mathrm{THz}$ gap" (no. KAW 2013.0049). L.O. acknowledges financial support from the Swedish Government Strategic Research Area in Materials Science on Functional Materials at Linköping University (Faculty Grant SFO Mat LiU no. 2009 00971). Supercomputing resources were provided by the Swedish National Infrastructure for Computing (SNIC) and the Swedish National Supercomputer Centre (NSC). Support from the Swedish research council VR-RFI (2017-00646 9) for the Accelerator-based ion-technological center and from the Swedish Foundation for Strategic Research (RIF14-0053) for the tandem accelerator laboratory in Uppsala is gratefully acknowledged. The authors acknowledge the Knut and Alice Wallenberg Foundation for support of the electron microscopy laboratory in Linköping (KAW 2015.0043).

\section{REFERENCES}

(1) Lakshmi, E. Dielectric Properties of Reactively Sputtered Gallium Nitride Films. Thin Solid Films 1981, 83, L137-L140.

(2) Strite, S.; Morkoç, H. GaN, AlN, and InN: A Review. J. Vac. Sci. Technol., B: Microelectron. Nanometer Struct.-Process., Meas., Phenom. 1992, 10, 1237-1266.

(3) Suzuki, M.; Uenoyama, T.; Yanase, A. First-Principles Calculations of Effective-Mass Parameters of AlN and GaN. Phys. Rev. B: Condens. Matter Mater. Phys. 1995, 52, 8132-8139.

(4) Porowski, S. Growth and Properties of Single Crystalline GaN Substrates and Homoepitaxial Layers. Mater. Sci. Eng. B 1997, 44, 407-413.

(5) Burk, A. A.; O’Loughlin, M. J.; Siergiej, R. R.; Agarwal, A. K.; Sriram, S.; Clarke, R. C.; MacMillan, M. F.; Balakrishna, V.; Brandt, C. D. $\mathrm{SiC}$ and $\mathrm{GaN}$ Wide Bandgap Semiconductor Materials and Devices. Solid-State Electron. 1999, 43, 1459-1464.

(6) GaN-Based Materials and Devices; Shur, M. S., Davis, R. F., Eds.; World Scientific Publishing Co. Pte. Ltd.: Singapore, 2004.
(7) Tamura, K.; Kuroki, Y.; Yasui, K.; Suemitsu, M.; Ito, T.; Endou, T.; Nakazawa, H.; Narita, Y.; Takata, M.; Akahane, T. Growth of GaN on $\mathrm{SiC} / \mathrm{Si}$ Substrates Using AlN Buffer Layer by Hot-Mesh CVD. Thin Solid Films 2008, 516, 659-662.

(8) Chen, J.-T.; Bergsten, J.; Lu, J.; Janzén, E.; Thorsell, M.; Hultman, L.; Rorsman, N.; Kordina, O. A GaN-SiC Hybrid Material for High-Frequency and Power Electronics. Appl. Phys. Lett. 2018, 113, 041605.

(9) Lu, J.; Chen, J.-T.; Dahlqvist, M.; Kabouche, R.; Medjdoub, F.; Rosen, J.; Kordina, O.; Hultman, L. Transmorphic Epitaxial Growth of AlN Nucleation Layers on SiC Substrates for High-Breakdown Thin GaN Transistors. Appl. Phys. Lett. 2019, 115, 221601.

(10) Liu, B. L.; Lachab, M.; Jia, A.; Yoshikawaa, A.; Takahashi, K. MOCVD Growth of Device-Quality GaN on Sapphire Using a ThreeStep Approach. J. Cryst. Growth 2002, 234, 637-645.

(11) Beaumont, B.; Gibart, P.; Faurie, J. P. Nitrogen Precursors in Metalorganic Vapor Phase Epitaxy of $(\mathrm{Al}, \mathrm{Ga}) \mathrm{N}$. J. Cryst. Growth 1995, 156, 140-146.

(12) Ivanov, S. V.; Shubina, T. V.; Komissarova, T. A.; Jmerik, V. N. Metastable Nature of InN and In-Rich InGaN Alloys. J. Cryst. Growth 2014, 403, 83-89.

(13) Ozgit, C.; Donmez, I.; Alevli, M.; Biyikli, N. Atomic Layer Deposition of GaN at Low Temperatures. J. Vac. Sci. Technol. 2012, 30, 01A124.

(14) Motamedi, P.; Dalili, N.; Cadien, K. A Route to Low Temperature Growth of Single Crystal GaN on Sapphire. J. Mater. Chem. C 2015, 3, 7428-7436.

(15) Alevli, M.; Haider, A.; Kizir, S.; Leghari, S. A.; Biyikli, N. Comparison of Trimethylgallium and Triethylgallium as "Ga" Source Materials for the Growth of Ultrathin GaN Films on Si (100) Substrates via Hollow-Cathode Plasma-Assisted Atomic Layer Deposition. J. Vac. Sci. Technol., A 2016, 34, 01A137.

(16) Ozgit-Akgun, C.; Goldenberg, E.; Okyay, A. K.; Biyikli, N. Hollow Cathode Plasma-Assisted Atomic Layer Deposition of Crystalline AlN, GaN and AlxGal-XN Thin Films at Low Temperatures. J. Mater. Chem. C 2014, 2, 2123-2136.

(17) Biyikli, N.; Ozgit, C.; Donmez, I. Low-Temperature SelfLimiting Growth of III-Nitride Thin Films by Plasma-Enhanced Atomic Layer Deposition. Nanosci. Nanotechnol. Lett. 2012, 4, 10081014.

(18) Banerjee, S.; Aarnink, A. A. I.; Gravesteijn, D. J.; Kovalgin, A. Y. Thermal Atomic Layer Deposition of Polycrystalline Gallium Nitride. J. Phys. Chem. C 2019, 123, 23214-23225.

(19) Waggoner, K. M.; Olmstead, M. M.; Power, P. P. Structural and spectroscopic characterization of the compounds $[\mathrm{Al}(\mathrm{NMe} 2) 3] 2$, $[\mathrm{Ga}(\mathrm{NMe} 2) 3] 2,[(\mathrm{Me} 2 \mathrm{~N}) 2 \mathrm{Al}\{\mu$-N $(\mathrm{H}) 1$-Ad $\}] 2$ (1-Ad = 1-adamantanyl $)$ and $[\{\mathrm{Me}(\mu-\mathrm{NPh} 2) \mathrm{Al}\} 2 \mathrm{NPh}(\mu-\mathrm{C} 6 \mathrm{H} 4)]$. Polyhedron 1990, 9, 257-263.

(20) Rouf, P.; O’Brien, N. J.; Buttera, S. C.; Martinovic, I.; Bakhit, B.; Martinsson, E.; Palisaitis, J.; Hsu, C.-W.; Pedersen, H. Epitaxial $\mathrm{GaN}$ using $\mathrm{Ga}(\mathrm{NMe} 2) 3$ and $\mathrm{NH} 3$ plasma by atomic layer deposition. J. Mater. Chem. C 2020, 8, 8457-8465.

(21) Gordon, R. G. Atomic Layer Deposition for Semiconductors. In Atomic Layer Deposition for Semiconductors; Hwang, C. S., Yoo, C. Y., Eds.; Springer US: New York, 2014, pp 15-46.

(22) Brazeau, A. L.; DiLabio, G. A.; Kreisel, K. A.; Monillas, W.; Yap, G. P. A.; Barry, S. T. Theoretical and Experimental Investigations of Ligand Exchange in Guanidinateligand Systems for Group 13 Metals. Dalton Trans. 2007, 3297-3304.

(23) Kenney, A. P.; Yap, G. P. A.; Richeson, D. S.; Barry, S. T. The Insertion of Carbodiimides into $\mathrm{Al}$ and $\mathrm{Ga}$ Amido Linkages. Guanidinates and Mixed Amido Guanidinates of Aluminum and Gallium. Inorg. Chem. 2005, 44, 2926-2933.

(24) Leman, J. T.; Barron, A. R.; Ziller, J. W.; Kren, R. M. Synthesis of 1,3-Diphenyltriazenide Complexes of Aluminium, Gallium and Indium: Crystal Structure of Tris(1,3-Diphenyltriazenido)Aluminium(III). Polyhedron 1989, 8, 1909-1912.

(25) O’Brien, N. J.; Rouf, P.; Samii, R.; Rönnby, K.; Buttera, S. C.; Hsu, C.-W.; Ivanov, I. G.; Kessler, V.; Ojamäe, L.; Pedersen, H. In- 
Situ Activation of an Indium(III) Triazenide Precursor for Epitaxial Indium Nitride by Atomic Layer Deposition. Chem. Mater. 2020, 32, 4481-4489.

(26) Ren, S. Y.; Dow, J. D. Lattice-matching SiC substrates with GaN. Appl. Phys. Lett. 1996, 69, 251-253.

(27) Blackman, A.; Gahan, L. Aylward and Findlay's SI Chemical Data, 7th ed.; John Wiley \& Sons: Milton, Qld, Australia, 2014.

(28) Xu, X.; Liu, H.; Shi, C.; Zhao, Y.; Fung, S.; Beling, C. D. Residual Donors and Compensation in Metalorganic Chemical Vapor Deposition As-Grown n-GaN. J. Appl. Phys. 2001, 90, 6130-6134.

(29) Neugebauer, J.; Van De Walle, C. G. Atomic Geometry and Electronic Structure of Native Defects in GaN. Phys. Rev. B: Condens. Matter Mater. Phys. 1994, 50, 8067-8070.

(30) Neugebauer, J.; Van de Walle, C. G. Gallium Vacancies and the Yellow Luminescence in GaN. Appl. Phys. Lett. 1996, 69, 503-505.

(31) Reshchikov, M. A.; Morkoç, H. Luminescence Properties of Defects in GaN. J. Appl. Phys. 2005, 97, 061301.

(32) Yu, G.; Wang, G.; Ishikawa, H.; Umeno, M.; Soga, T.; Egawa, T.; Watanabe, J.; Jimbo, T. Optical Properties of Wurtzite Structure GaN on Sapphire Aroundfundamental Absorption Edge (0.78-4.77 EV) by Spectroscopicellipsometry and the Optical Transmission Method. Appl. Phys. Lett. 1997, 70, 3209-3211.

(33) Swetha, M.; Ramana, P. V.; Shirodkar, S. G. Simple and Efficient Method for the Synthesis of Azides in Water-THF Solvent System. Org. Prep. Proceed. Int. 2011, 43, 348-353.

(34) Frisch, M. J.; Trucks, G. W.; Schlegel, H. B.; Scuseria, G. E.; Robb, M. A.; Cheeseman, J. R.; Scalmani, G.; Barone, V.; Petersson, G. A.; Nakatsuji, H.; et al. Gaussian 16 Revision B.01, 2016.

(35) Becke, A. D. Density-functional thermochemistry. III. The role of exact exchange. J. Chem. Phys. 1993, 98, 5648-5652.

(36) Lee, C.; Yang, W.; Parr, R. G. Development of the ColleSalvetti Correlation-Energy Formula into a Functional of the Electron Density. Phys. Rev. B: Condens. Matter Mater. Phys. 1988, 37, 785789.

(37) Grimme, S.; Antony, J.; Ehrlich, S.; Krieg, H. A Consistent and Accurate $\mathrm{Ab}$ Initio Parametrization of Density Functional Dispersion Correction (DFT-D) for the 94 Elements H-Pu. J. Chem. Phys. 2010, 132, 154104.

(38) Weigend, F.; Ahlrichs, R. Balanced Basis Sets of Split Valence, Triple Zeta Valence and Quadruple Zeta Valence Quality for H to Rn: Design and Assessment of Accuracy. Phys. Chem. Chem. Phys. 2005, 7, 3297-3305.

(39) Metz, B.; Stoll, H.; Dolg, M. Small-Core MulticonfigurationDirac-Hartree-Fock-Adjusted Pseudopotentials for Post-d Main Group Elements: Application to $\mathrm{PbH}$ and $\mathrm{PbO}$. J. Chem. Phys. 2000, 113, 2563-2569.

(40) Rouf, P.; O’Brien, N. J.; Rönnby, K.; Samii, R.; Ivanov, I. G.; Ojamäe, L.; Pedersen, H. The Endocyclic Carbon Substituent of Guanidinate and Amidinate Precursors Controlling Atomic Layer Deposition of InN Films. J. Phys. Chem. C 2019, 123, 25691-25700.

(41) Mayer, M.; Eckstein, W.; Langhuth, H.; Schiettekatte, F.; Von Toussaint, U. Computer Simulation of Ion Beam Analysis: Possibilities and Limitations. Nucl. Instrum. Methods Phys. Res., Sect. B 2011, 269, 3006-3013.

(42) Ström, P.; Petersson, P.; Rubel, M.; Possnert, G. A Combined Segmented Anode Gas Ionization Chamber and Time-of-Flight Detector for Heavy Ion Elastic Recoil Detection Analysis. Rev. Sci. Instrum. 2016, 87, 103303.

(43) Janson, K.S. CONTES; Uppsala University: Sweden, 2004.

(44) Arstila, K.; Julin, J.; Laitinen, M. I.; Aalto, J.; Konu, T.; Kärkkäinen, S.; Rahkonen, S.; Raunio, M.; Itkonen, J.; Santanen, J.-P.; et al. Potku-New Analysis Software for Heavy Ion Elastic Recoil Detection Analysis. Nucl. Instrum. Methods Phys. Res., Sect. B 2014, 331, 34-41.

(45) Zhang, Y.; Whitlow, H. J.; Winzell, T.; Bubb, I. F.; Sajavaara, T.; Arstila, K.; Keinonen, J. Detection Efficiency of Time-of-Flight Energy Elastic Recoil Detection Analysis Systems. Nucl. Instrum. Methods Phys. Res., Sect. B 1999, 149, 477-489.
(46) Arvizu, M. A.; Wen, R.-T.; Primetzhofer, D.; Klemberg-Sapieha, J. E.; Martinu, L.; Niklasson, G. A.; Granqvist, C. G. Galvanostatic Ion Detrapping Rejuvenates Oxide Thin Films. ACS Appl. Mater. Interfaces 2015, 7, 26387-26390.

(47) Qu, H.-Y.; Primetzhofer, D.; Arvizu, M. A.; Qiu, Z.; Cindemir, U.; Granqvist, C. G.; Niklasson, G. A. Electrochemical Rejuvenation of Anodically Coloring Electrochromic Nickel Oxide Thin Films. ACS Appl. Mater. Interfaces 2017, 9, 42420-42424.

(48) Ziegler, J. F.; Ziegler, M. D.; Biersack, J. P. SRIM-The Stopping and Range of Ions in Matter (2010). Nucl. Instrum. Methods Phys. Res., Sect. B 2010, 268, 1818-1823. 